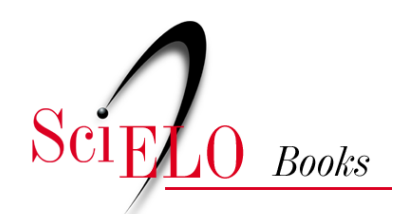

\title{
Movimentações e relações com a natureza dos Kaingang em territórios da bacia hidrográfica Taquari-Antas e Caí, Rio Grande do Sul
}

\author{
Luís Fernando da Silva Laroque
}

\section{SciELO Books / SciELO Livros / SciELO Libros}

LAROQUE, L.F.S. Movimentações e relações com a natureza dos Kaingang em territórios da bacia hidrográfica Taquari-Antas e Caí, Rio Grande do Sul. In: GERHARDT, M., NODARI, E.S., and MORETTO, S.P., eds. História ambiental e migrações: diálogos [online]. São Leopoldo: Oikos; editora UFFS, 2017, pp. 157-175. ISBN: 978-85-64905-68-9.

https://doi.org/10.7476/9788564905689.0011.

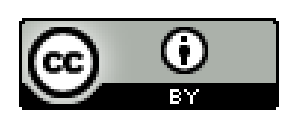

All the contents of this work, except where otherwise noted, is licensed under a Creative Commons Attribution 4.0 International license.

Todo o conteúdo deste trabalho, exceto quando houver ressalva, é publicado sob a licença Creative Commons Atribição 4.0.

Todo el contenido de esta obra, excepto donde se indique lo contrario, está bajo licencia de la licencia $\underline{\text { Creative Commons }}$ Reconocimento 4.0. 


\section{Movimentações e relações com a natureza dos Kaingang em territórios da bacia hidrográfica Taquari-Antas e Caí, Rio Grande do Sul}

Luís Fernando da Silva Laroque

\section{Introdução}

O Kaingang é um povo pertencente ao Grupo Linguístico Macro-Jê, família dos Jês Meridionais, que, atualmente, totaliza em torno de 38 mil pessoas (IBGE, 2012). Tradicionalmente, conforme Laroque (2009), encontravam-se estabelecidos em territórios localizados nas bacias hidrográficas dos rios Tietê, Feio, Aguapeí e Paranapanema (São Paulo); bacias hidrográficas dos rios Tibagi, Ivaí, Piquiri e Iguaçu (Paraná); e bacias hidrográficas entre os rios Iguaçu e Uruguai (em Santa Catarina). Avançavam pelos territórios das bacias hidrográficas dos rios Peperi-Guaçu e Santo Antônio (Misiones, na Argentina) e ainda sobre os territórios das bacias hidrográficas do Lago Guaíba, rios Jacuí, Sinos, Caí, Taquari-Antas e Uruguai (no Rio Grande do Sul).

A presença no território, as movimentações e sua relação com a natureza estão diretamente relacionadas ao mito de origem, segundo o qual os ancestrais Kamé e Kayrucré, na serra do Crijijimbé(Serra Geral), norteiam a cosmologia indígena (BORBA, 1908; NIMUENDAJÚ, 1993). No decorrer do processo histórico, esta cosmologia foi sendo reelaborada, e as representações simbólicas conferem sentidos às suas práxis materiais e sociais.

O objetivo deste estudo consiste em analisar os indígenas Kaingang na perspectiva das movimentações e das relações com a natureza no decorrer dos séculos XIX, XX e XXI, em territórios da bacia hidrográfica do Taquari-Antas e Caí. A metodologia, com base em aportes teóricos de autores que estudam a territorialidade e a História Ambiental, como Seeger e Castro (1979), Ramos (1988), Little (1994), Tommasino (1995, 2000 
e 2004), Worster (1991), Dean (1996), Corrêa (2008) e Bublitz (2008), caracteriza-se por uma abordagem qualitativa com análise de conteúdo. Os dados foram coletados em revisão bibliográfica, em fontes documentais do Arquivo Histórico do Rio Grande do Sul, nas produções do projeto de pesquisa "Arqueologia, História Ambiental e Etno-história", coordenado por Neli Galarce Machado, e nas pesquisas de campo e nas produções do projeto de pesquisa, "Identidades étnicas em espaços territoriais da Bacia Hidrográfica do Taquari-Antas/RS: história, movimentações e desdobramentos socioambientais" e do projeto de extensão "História e cultura Kaingang em territórios da Bacia Hidrográfica do Taquari-Antas", ambos coordenados por Luís Fernando Laroque, e vinculados ao Programa de Pós-Graduação em Ambiente e Desenvolvimento da Universidade do Vale do Taquari (Univates).

\section{Movimentações e territorialidade Kaingang ao sul do Brasil Meridional}

No Rio Grande do Sul, do início da Conquista Ibérica até o século XIX, os indígenas Kaingang ocupavam territórios que se estendiam desde o Rio Uruguai até o Rio Jacuí, mais precisamente nos limites compreendidos "[...] a noroeste, o Rio Piratini; a nordeste, o Rio Pelotas, baixando até o Litoral no Município de Torres; ao sul, a mata das bacias dos rios Caí, Taquari e Jacuí, isto é, a região entre os meridianos de $50^{\circ}$ e $55^{\circ}$ oeste de Greenwich, e os paralelos, aproximadamente, de $27^{\circ} 50^{\prime}$ e $29^{\circ} 50^{\prime}$ de latitude sul" (BECKER, 1975, p. 40). Na literatura também aparecem com o nome de Ibiraiaras, Guananases, Caaguás, Coroados, Bugres, entre outros, conforme aparece no mapa (Figura 1). Do ponto de vista sociopolítico, organizavam-se em parcialidades comandadas por um Pã'í mbâng (liderança principal), bem como, os Pã'í (lideranças menores), que, por sua vez, representam as várias famílias do grupo. 
Figura 1: Tradicionais territórios Kaingang no Rio Grande do Sul

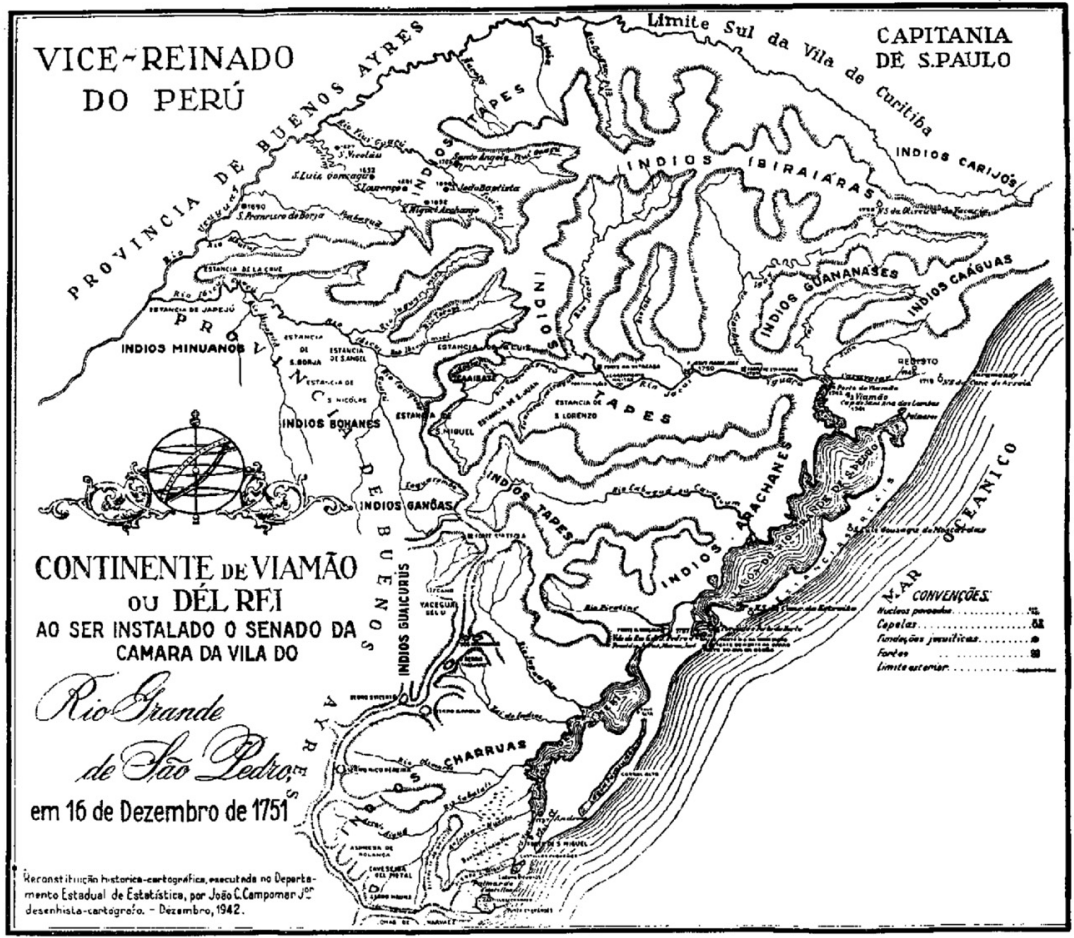

Fonte: Silva (1968)

Na visão das Sociedades Indígenas, o conceito de ambiente, sobretudo o de território, não é apenas o lugar geográfico de onde são obtidos os recursos para a subsistência, mas, sim, um espaço "de dimensões sóciopolítico-cosmológicas mais amplas” (SEEGER; CASTRO, 1979, p.104). Nesse sentido, segundo Ramos (1988, p. 14), a concepção de ambiente e limite territorial não é estranha às sociedades nativas, mas, sim, "o sentido de exclusividade e de policiamento de um território" nos moldes concebidos pela Sociedade Colonial e Pós-colonial.

Frente a essa divergência de concepções, situações envolvendo questões territoriais entre os Kaingang, Guarani e, posteriormente, os não índios, tais como os colonizadores lusos e imigrantes alemães e italianos em territórios da bacia hidrográfica Taquari-Antas nos parecem não ser tão rígidas, porque, mesmo guerreando entre si, estes grupos étnicos conviveram num mesmo território, tanto antes quanto após a chegada dos coloni- 
zadores. Na concepção Kaingang, segundo Tommasino (2000), as categorias espaciais são as "emã" (aldeias fixas), construídas em áreas de campo; e os "wãre" (abrigos provisórios), instalados nas florestas e nas margens dos rios, onde permaneciam por semanas ou meses e estabeleciam os diversos sistemas de representação e conexões entre o mundo natural (homens, animais, plantas) e o sobrenatural (espíritos humanos, espíritos animais e espíritos das plantas).

Corrobora para a questão o fato de que, no estado do Paraná, ainda conforme Tommasino (1995), os Kaingang utilizavam os grandes rios para delimitar os territórios e os rios menores para estabelecer os domínios de cada subterritório, fronteiras naturais e sociais que eram respeitadas em suas movimentações. Isto é, enquanto os rios Paranapanema, Ivaí, Piquiri e Iguaçu tornaram-se obstáculos naturais e sociais para delimitar os territórios de grupos Kaingang rivais, os afluentes deles, por sua vez, limitavam os subterritórios ocupados pelos grupos menores. Laroque (2000), transpondo essa interpretação para os demais territórios Kaingang, como é o caso do Rio Grande do Sul, defende a hipótese de que grandes rios como o Uruguai, o Inhacorá, o Guarita, o Passo Fundo, o Jacuí, o Sinos, o Caí e o Taquari-Antas, estes últimos selecionados para o presente estudo, servissem como demarcadores de limites fronteiriços dos territórios ocupados pelas parcialidades das lideradas Kaingang de Fongue, Nonohay, Votouro, Nicafim, bem como, Braga, Yotoahé e Nicué, que viviam em áreas da bacia hidrográfica Taquari-Antas e Caí, possível de observar no mapa (Figura 2).

Considerando que os conceitos de natureza e sociedades são produzidos culturalmente, especificamente para os indígenas Kaingang, o ambiente e, consequentemente, sua história ambiental constituem-se num entrelaçamento, envolvendo relações de reciprocidade entre o universo humano e o não humano. Nesse sentido, temos:

Na concepção Kaingang, cada ambiente é habitado por seres naturais e sobrenaturais; as matas contêm animais, vegetais e seres sobrenaturais. Portanto, ao mundo visível corresponde um mundo invisível, que é necessário reconstituir. A mata possui um espírito-guardião ou "dono", que é o nem tãn. O rio tem o seu gój tãn; a serra, o seu krín tãn, e assim por diante. Sendo a natureza múltipla, também são múltiplos os "espíritos-donos" (TOMMASINO, 2004, p. 159).

Do ponto de vista geomorfológico e ambiental, o tradicional território Kaingang no Rio Grande do Sul compreendia três regiões fitogeográficas associadas à Mata Atlântica, como é o caso da Floresta Ombrófila Mis- 
ta, da Floresta Estacional Decidual e dos Campos (Savana ou Estepes). No que diz respeito às ocupações Jê Meridionais no Período Pré-Colonial, bem como, do século XVI ao XVIII, estudos arqueológicos têm demonstrado o manejo ambiental envolvendo plantas, tais como pinhão, milho, amendoim, abóbora, palmito e medula da palmeira; a caça de animais, como é o caso de antas, porco-do-mato, espécies de aves e a coleta de mel e larvas; e também a pesca de espécies de peixes. Sendo assim, trata-se de um espaço repleto de significado social e simbólico, onde, portanto, a territorialidade Kaingang se expressa envolvendo relações entre ser humano e natureza.

Figura 2: Movimentações de parcialidades Kaingang no tradicional território

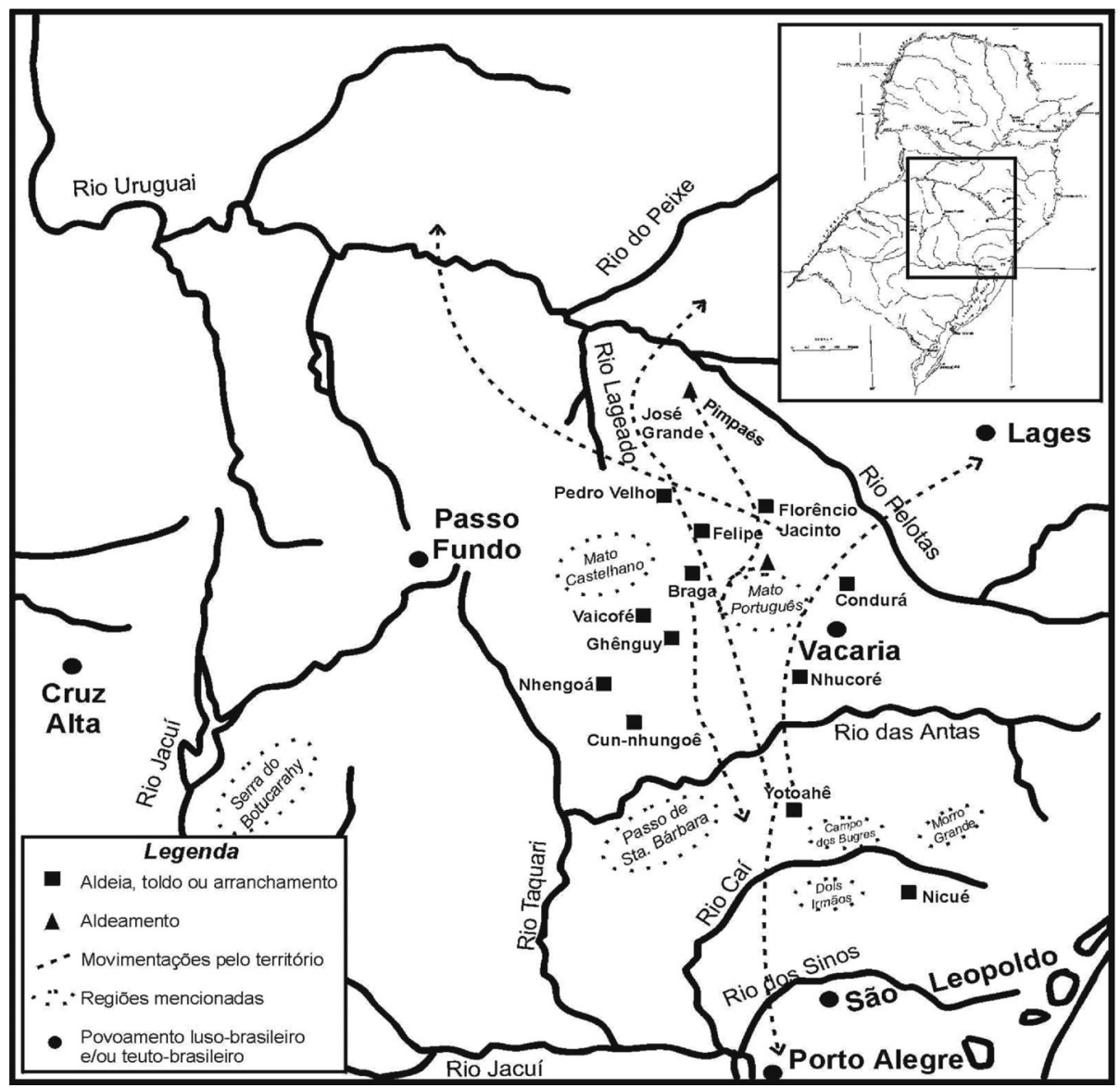

Fonte: Laroque (2000, p. 151) 


\section{Movimentações e processos de (des)territorialidade Kaingang em áreas da bacia hidrográfica Taquari-Antas e Caí no século XIX}

Na Província de São Pedro do Rio Grande do Sul, inserida no projeto colonizador de fins do século XVIII e século XIX, temos a chegada dos imigrantes açorianos, alemães e italianos. Seguindo dinâmicas internas do povoamento, são estabelecidos em pequenas áreas, principalmente, em territórios nos vales dos rios Jacuí, Sinos, Caí e Taquari-Antas, o que contribui para as movimentações indígenas e o processo de (des)territorialidade Kaingang.

Vale salientar, sobretudo a partir de 1757, que os espaços territoriais da bacia do Taquari-Antas, que até então pertenciam aos Campos de Viamão, desmembram-se destes e passam a fazer parte da freguesia de Triunfo (KUHN, 2004; CHRISTILLINO, 2004). Nesse contexto de meados do século XVIII até meados do século XIX, frentes expansionistas e reconfigurações fundiárias são responsáveis pela instalação das primeiras sesmarias e fazendas em territórios da bacia hidrográfica Taquari-Antas, como é o caso da Sesmaria de José da Silva Lima, em 1798; a Sesmaria de João Inácio Teixeira, em 1800; a Sesmaria de Francisco Antonio de Souza, em 1813; a Sesmaria de Ricardo Vila Nova, em 1815; a Fazenda da Estrella, em 1830, de posse de Victorino José Ribeiro; e a Fazenda dos Conventos, 1846, de posse de Francisco Silvestre Ribeiro (VEDOY, 2015; GREGORY, 2015).

A contrapartida Kaingang constitui-se em investidas guerreiras contra o colonizador que adentrava seu tradicional territorial, como é o caso do conflito ocorrido em 1836, na Fazenda da Estrella, quando o pardo Joze Antonio é morto a flechada (CORRESPONDÊNCIA 19 dez. 1836). Situação semelhante ocorre no ano de 1845, quando os Kaingang movimentamse por áreas dos rios Taquari e Caí, eles revidam a presença dos colonizadores em seus territórios de coleta, caça e pesca.

\footnotetext{
Não posso deixar de significar a V. $S^{a}$ que não mi consta que este Districto fosse invadido pelos selvagens, antes do dia 29 de Janeiro dia em que V. S ${ }^{a}$ datou seo Officio, e que a requisição foi feita por prevenção para guardar-se lugares que o ano passado forão amiaçados e que por isso fiquei privado de fazer a perseguição onde elles apparecerão por estar esperando que seria attendida a requisição que fis ao mesmo Delegado. V. $S^{\mathrm{a}}$ deve estar ao facto que os selvagens todos os veroens costumão descer a serra e atacar as habitações dos pacíficos moradores, não só deste districto como do Cahy, Santo
} 
Amaro e como ultimamente aconteceo nas Fazendas de Francisco Silvestre Ribeiro, Maria Francisca do Rosário, Amaro Rodrigues, (CORRESPONDÊNCIA, 15 fev. 1845).

Em se tratando dos territórios Kaingang mais próximos da bacia hidrográfica do Caí, muitos dos quais estavam sendo transformados em colônias para atender aos interesses do projeto envolvendo a imigração alemã, cujo núcleo inicial foi a Feitoria do Linho Cânhamo/São Leopoldo, apontam-se conflitos com parcialidades indígenas, possivelmente lideradas por Braga, Yotoahé e Nicué, contra estes colonizadores. Ilustram a situação, incursões guerreiras dos Kaingang em áreas da Colônia Feliz, envolvendo a família de Jacó Bohn, em 1843; e a de Robert Kunzel, em 1858/1859, bem como em territórios da Colônia Santa Maria da Soledade contra a família Languendock, em 1857/1858 e a família de Lamberto Wersteg, em 1868, conforme se identifica no mapa (Figura 3).

Figura 3: Conflitos entre Kaingang e colonizadores em territórios da Bacia Hidrográfica Taquari-Antas e Caí

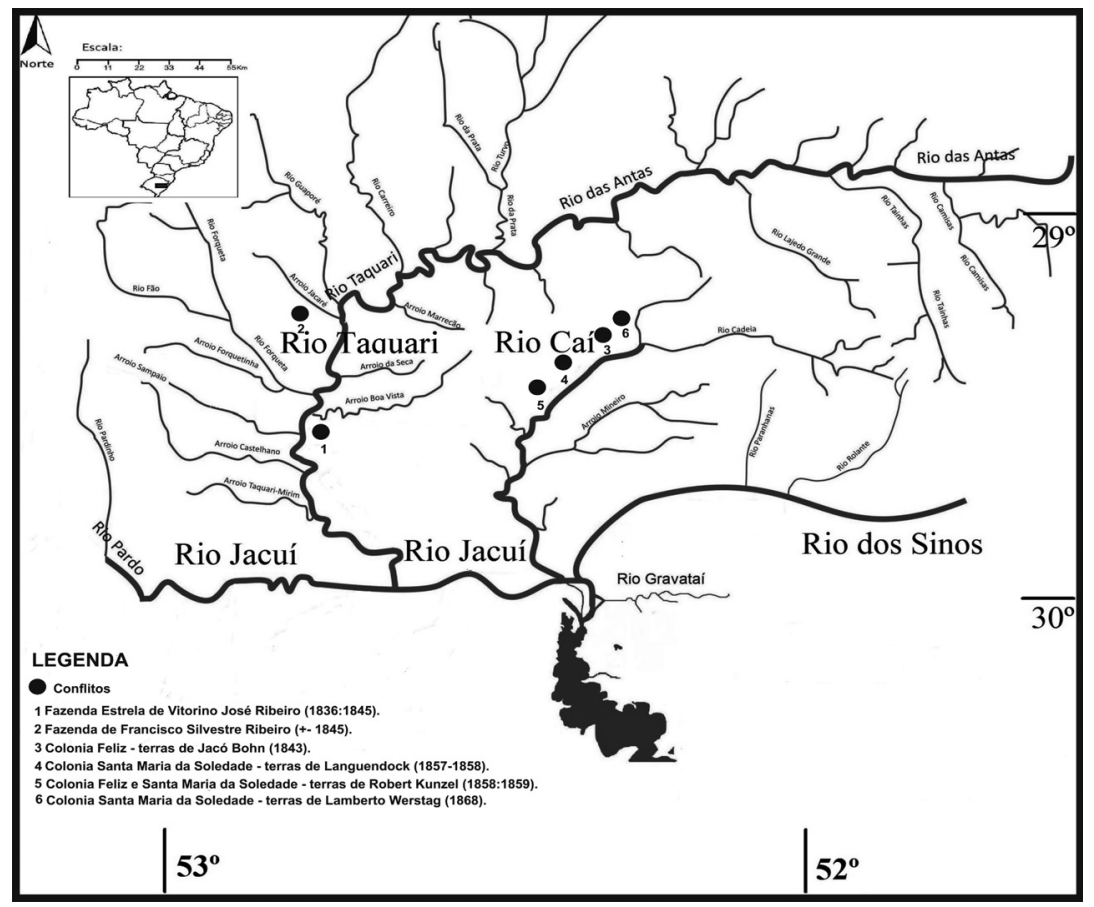

Fonte: Vedoy $(2015$, p. 81) 
O ambiente territorial das bacias hidrográficas do Taquari-Antas e Caí também se insere no contexto fitogeográfico caracterizado pela predominância centro-norte da Floresta Ombrófila Mista e na porção centro-sul, da Floresta Estacional Decidual. Segundo Wolf (2016), em sua pesquisa arqueológica sobre estruturas subterrâneas Jê no território, a vegetação é composta por Araucaria angustifolia, árvores, arbustos e várias espécies de Myrtaceae com presença de inúmeras frutíferas. Entre as espécies de animais, aponta-se o veado-campeiro, o bugio, a anta, a cutia, o tatu-galinha, o ratão-do-banhado, o porco-do-mato, a paca, o aracuã, a saracura, o inambu, a marreca-pé-vermelho, o tucano-de-bico-verde, o lambari, a piava, o pintado, o dourado, o jundiá, o cascudo e o cará.

Com base na perspectiva analítica de Little (1994), tendo em vista as atividades de subsistência material e a reprodução social presente na memória do grupo, em nosso entendimento, a ocupação e a movimentação das parcialidades Kaingang nos territórios em estudo foram constantes, tanto antes ou mesmo durante os primeiros contatos com o projeto colonizador no século XIX. O engenheiro Afonso Mabilde, que conviveu com os indígenas Kaingang durante suas atividades como agrimensor na abertura de estradas do Pontão até o Caí, relata:

Os pinheirais em que os selvagens têm seu alojamento são repartidos e divididos e em territórios correspondentes, em tamanho, ao número de indivíduos que componham as tribos. Cada tribo subordinada com o seu chefe (cacique subordinado) tem o seu alojamento particular (todos juntos formam o alojamento geral), em territórios que lhe é indicado pelo cacique principal. Este pequeno alojamento sempre se acha situado sobre um caminhozinho que segue de uma a outra tribo, geralmente passando pelo centro do pinheiral, em direção longitudinal à serra a qual se acha o mesmo situado. $[\ldots]$

O território do pinheiral, compreendido entre duas marcas, pertence exclusivamente à tribo que nele habita por ordem do cacique principal e nesse território é que todos os indivíduos daquela tribo apanham o pinhão para seu sustento. A invasão de outra tribo, para esse fim, é motivo de uma guerra de extermínio, para a qual são convocadas todas as demais tribos (MABILDE, 1983, p. 126-127).

Nesse contexto, é possível perceber a existência de duas lógicas operantes no que se refere à história ambiental: a dos indígenas e a dos colonizadores. Ou seja, enquanto os Kaingang se relacionam com a natureza a partir das relações de reciprocidade e da memória, presentes no mito de origem, os colonizadores, sejam eles fazendeiros ou imigrantes, partem do 
pressuposto do "espaço vazio", situação que legitimava seu estabelecimento no território, semelhante aos relatos analisados por Dora Corrêa, em fins do século XVIII, na Capitania de São Paulo, ao salientar que "[...] induzem o leitor a imaginar tanto vazios humanos e, portanto, culturais, quanto um território indígena, Xakclan (Kaingang), dentro das fronteiras fixadas pelo Tratado de Madri" (CORRÊA, 2008, p. 137).

Assim, a diminuição do ambiente por causa da (des)territorialização indígena nos possibilita compreender as investidas Kaingang nas fazendas e colônias mencionadas, localizadas em áreas da bacia hidrográfica do Taquari-Antas e Caí. Ou seja, os eventos envolvendo a busca de alimentos para a sustentabilidade, como, por exemplo, animais domésticos, milho, mandioca, feijão, abóbora, entre outros, como também as incursões guerreiras, precisam ser analisados no sentido social e simbólico, considerando a existência de uma rede de alianças e de conflitos intrínseca entre as parcialidades Kaingang, detentoras de prestígio, que faz parte da própria identidade Kaingang.

Juliana Bublitz (2008) salienta que as relações dos imigrantes com a floresta subtropical consistia na derrubada da vegetação para impor o domínio sobre a natureza, entretanto, não podemos descartar um misto de medo e admiração, porque, conforme afirma Warren Dean (1996), no estudo sobre a mata atlântica brasileira, a floresta é vista como um lugar inóspito para os humanos. Esta situação não era diferente no Rio Grande do Sul, pois, pelo imaginário da época, a floresta estava repleta de tigres, cobras, onças, além dos indígenas Kaingang. Ilustrando situações envolvendo a (des) territorialidade Kaingang, considerando suas investidas que dificultavam o desenvolvimento e o progresso das colônias, em ambientes da margem direita da bacia hidrográfica do Caí, temos um relato do ex-inspetor colonial Adalberto Jahn, publicado em 1871, informando o seguinte:

Quando em 1832 os habitantes da Picada Dous Irmãos forão extraordinariamente incommodados pelos indígenas selvagens, resolverão quatro moços robustos e corajosos estabelecer-se nos fundos dos primeiros dezesseis prazos coloniaes da ala de Leste da dita Picada, e ahi fundarão a Linha denominada: Quatro Colônias, constituindo-se assim uns baluartes contra aquelles indígenas [...] Passados os anos, não havia mais o que recear de taes selvagens (JAHN apud BUBLITZ, 2008, p. 328).

Tendo em vista a efetivação da colonização que passava pela liberação dos tradicionais territórios Kaingang, o governo da Província de São Pedro do Rio Grande do Sul, conforme Nonnenmacher (2000), em fins de 
1845 e início do ano de 1846, recorre à política dos Aldeamentos Indígenas, como é o caso de Guarita, Nonoai e Campo do Meio. Isto é, instigavase um processo de deslocamentos dos Pã'í mbâng e Pã'í com as parcialidades indígenas que lideravam para o norte da província e legalizava-se o processo de (des)territorialidade Kaingang, em áreas das bacias hidrográfica do Taquari-Antas e do Caí.

\section{Movimentações e processo de (re)territorialidade Kaingang em áreas da bacia hidrográfica Taquari-Antas e Caí no século XX e XXI}

Efetivada a colonização no decorrer do século XIX, a partir das primeiras décadas do século XX, no Rio Grande do Sul, ocorre a multiplicação de cidades, situação que atinge regiões dos tradicionais territórios indígenas, como é o caso de áreas da bacia hidrográfica do Taquari-Antas, do Caí, do Sinos e do Lago Guaíba. Assim, neste contexto, insere-se o processo de (re)territorialidade Kaingang, em espaços presentes em sua memória, mas agora localizados em contextos urbanos, entre os quais apontam-se as comunidades indígenas Jamã Tÿ Tãnh, em Estrela; Foxá, em Lajeado; Pó Mág, em Tabaí; Pó Nãnh Mág, em Farroupilha, localizadas no mapa (Figura 4). Mas também temos a Por Fi Gâ, em São Leopoldo; bem como a Jamã Fág Nhin (na Lomba do Pinheiro), Rhátej (no Morro Santana) e Jamã Tupeng Pó (Morro do Osso), em Porto Alegre.

Esse fenômeno não é algo novo, considerando que Roberto Cardoso de Oliveira (1968) já chamava atenção que aldeias urbanas devem ser entendidas como forma de manutenção da cultura e da memória tribal. Situações recentes nesse sentido são os estudos de Baines (2001); Mussi (2006); Nunes (2010); Rosado e Fagundes (2013); Lappe e Laroque (2015); Souza, Haetinger e Laroque (2016).

Especificamente nos territórios da bacia hidrográfica Taquari-Antas, situa-se a Terra Indígena Jamã Tÿ Tãhn, localizada no Km 360 da BR 386, sob jurisdição do município de Estrela. Os Kaingang, conforme Silva (2016), deslocando-se da Gruta dos Índios em Santa Cruz do Sul, estabeleceram-se na área, em meados da década de 1960, possivelmente, pertencente a uma parcialidade que não aceitou fixar-se nos aldeamentos indígenas durante o século XIX e continuou a movimentar-se pelo território. A terra indígena 
conta com 15 ha de área ocupada, onde vivem 29 famílias, totalizando aproximadamente 150 pessoas. No local, há 29 casas, um centro cultural e uma escola. A liderança é exercida pelo cacique Carlos Soares e pelo vice-cacique Vanderlei de Melo. Vale salientar que o processo de (re) territorialidade neste local deve-se ao fato de o umbigo do patriarca da comunidade, Manoel Soares, estar enterrado nesta região (GONÇALVES, 2008). Portanto, a escolha do lugar para os Kaingang, conforme Nimuendajú (1993), tem um significado cultural, por envolver uma intrínseca relação entre terra, cultura e natureza.

Figura 4: Comunidades Kaingang e territórios da bacia hidrográfica Taquari-Antas e Caí

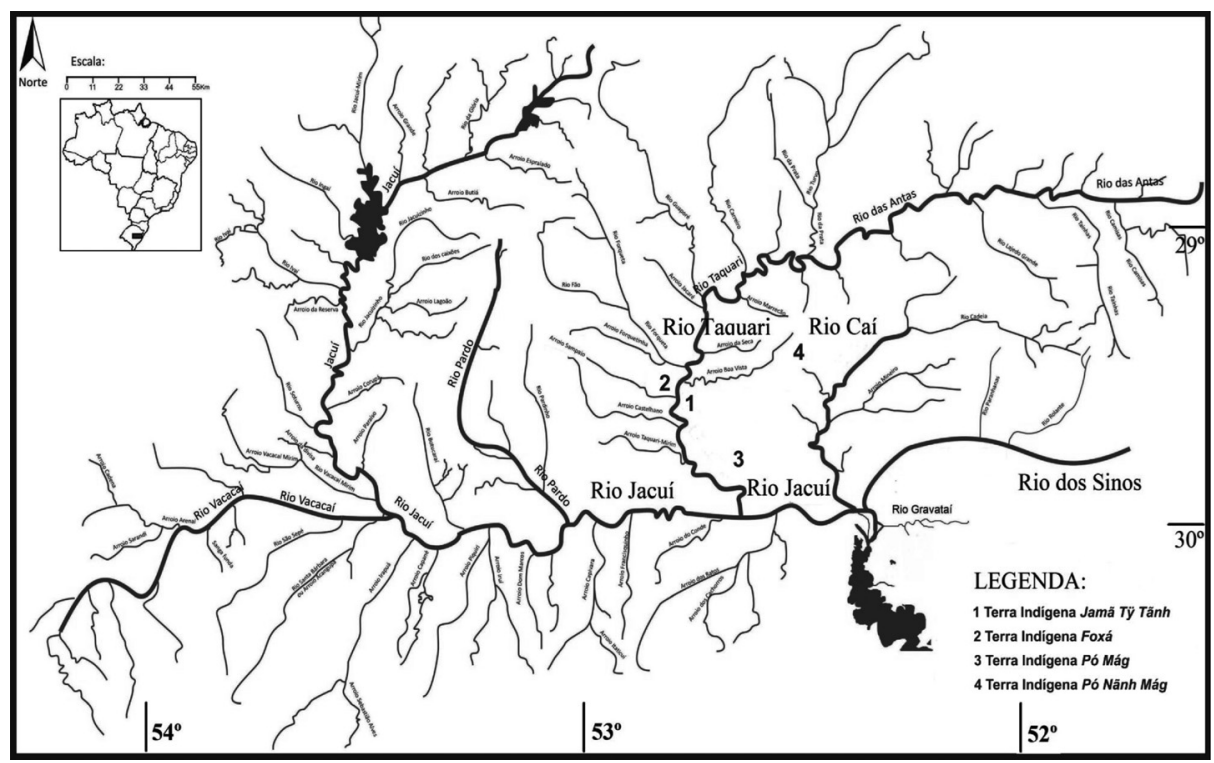

Fonte: Acervo Projeto História e Cultura Kaingang/Univates, Lajeado/RS

Há, também, os Kaingang da Terra Indígena Foxá, que se localiza no Km 67 da RS-130, na cidade de Lajeado. Em fins do século XX e início do século XXI, deslocaram-se de Nonoai, Guarita, Votouro e Serrinha, também num processo de (re)territorialidade, para áreas da bacia hidrográfica Taquari-Antas. Estabeleceram-se, inicialmente, nas proximidades da rodoviária do município de Lajeado e, posteriormente, onde se localiza a comunidade indígena em questão (LAPPE, 2015). Esta terra indígena tem uma 
área ocupada de 5,8 ha, onde se concentram, em média, 25 famílias, que totalizam 100 pessoas. A área contém 15 casas, uma escola e barracas improvisadas para comercializar o artesanato. A liderança é exercida pelo cacique Vicente Garcia pelo vice-cacique Jocelino. Segundo as categorias espaciais e temporais Kaingang propostas por Tommasino (2000), a presença destes Kaingang em territórios da bacia do Taquari-Antas, inicialmente, pode ser considerada um wãre (acampamento provisório) e, posteriormente, um emã (aldeia fixa). Se, no passado (wãxi), estabeleciam-se a fim de coletar cipós, caçar e pescar, no tempo atual (uri), visam a encontrar melhores condições de vida, sobretudo, relacionadas a locais próximos de matas, onde seja possível coletar materiais para a confecção de artesanato e sua posterior comercialização.

A Terra Indígena Pó Mág surgiu no ano de 2013. Localiza-se no km 385 da BR 386, na área de jurisdição do município de Tabaí. Trata-se de um desdobramento da Terra Indígena Foxá, em decorrência de medidas compensatórias da duplicação da BR $386^{1}$, empreendimento que impactou diretamente nos Kaingang estudados neste trabalho. Os Kaingang desta comunidade são oriundos de Nonoai, Voutouro, Tenente Portela ou provenientes de deslocamentos internos das aldeias localizadas em contextos urbanos nas cidades de Lajeado, São Leopoldo e de Porto Alegre. A área ocupada desta terra indígena é de 1,16 ha, onde vivem 9 famílias que somam uma média de 40 pessoas. Há, nesta área, 4 casas, 1 escola e um galpão improvisado para confeccionar o artesanato. A liderança do grupo é exercida pelo cacique André Fongue, e a vice-liderança, pelo cacique Joel. Salienta-se que o processo de (re)territorialidade dos Kaingang da Pó Mág não se diferencia das demais, tendo em vista que seu estabelecimento em territórios da Bacia Taquari-Antas "[...] diz respeito à sua manutenção cultural, em dar continuidade às suas práticas rituais assim como [...] seu relacionamento com as outras dimensões pela qual perpassam sua sociedade, o não humano e a natureza [...]" (BUSOLLI, 2015, p. 97).

Nos territórios da bacia hidrográfico do Caí, aponta-se a Terra Indígena Pó Nãnh Mág, localizada na Estrada da Linha Julieta, 722, Linha San-

\footnotetext{
${ }^{1}$ Com vista a fomentar o desenvolvimento econômico da Região Vale do Taquari/Rio Grande do Sul, a duplicação da BR 386 recebeu investimentos do Programa de Aceleração do Crescimento (PAC) do governo federal. Mas como o empreendimento atingiu diretamente uma comunidade Kaingang e indiretamente seis, o EIA/RIMA exigiu medidas compensatórias e mitigatórias, dentre as quais a aquisição de terras.
} 
ta Rita, município de Farroupilha, que, desde 2006, conta com a presença dos Kaingang. Segundo Invernizzi (2015), este processo de (re)territorialidade indígena também se insere nos deslocamentos dos Kaingang provenientes dos antigos aldeamentos de Guarita, Nonoai, bem como de Tenente Portela, Cacique Doble, Ligeiro e Carreteiro, sobretudo, a partir de 1999, quando são intensificados em direção aos territórios de planalto, mais precisamente, entre a bacia hidrográfica do Sinos e a bacia hidrográfica do Taquari-Antas. A Terra Indígena Pó Nãnh Mág constitui-se de uma área ocupada de 0,78 ha, onde vivem aproximadamente 15 famílias, totalizando 60 pessoas. Conta com 12 casas, uma escola, um centro cultural, sob a liderança da cacique Silvana Kréntãnh Antônio e um grupo de aconselhadores.

Sendo assim, compreendemos estas movimentações e processos de (re)territorialidade como resultantes da expropriação imposta aos Kaingang, durante a colonização, mas, também, devido às dinâmicas internas e externas do grupo, uma vez que a memória, a vida nos aldeamentos e o tempo dos antigos (wãxi) continuam operantes, tanto no espaço da aldeia (emã) e dos acampamentos provisórios (wãre), quanto no tempo atual (uri), onde passado e presente são orquestrados simbolicamente. Corroborando com a questão, o estudo de Tommasino sobre os Kaingang do Paraná traz a seguinte explicação:

Minha pesquisa revelou que os Kaingang se (re)territorializaram nos seus antigos territórios, hoje invadidos pelas cidades e fazendas [...]. Apesar de todas as tentativas de apagá-los enquanto grupo étnico, os Kaingang continuaram a se deslocar de acordo com seu sistema próprio, construído ao longo da sua história de contato. Mantiveram parte de seus costumes antigos que foram redefinidos, e foram inventando novos padrões, sempre de acordo com os princípios da lógica Kaingang. Se é evidente que muitos elementos da cultura nacional estão presentes na vida dos Kaingang, há muitos aspectos não evidentes que revelam o quanto as aparências são enganadoras. Sob a aparência de uma 'integração' e 'assimilação', escondem-se significados, representações e símbolos que revelam que o universo prático-simbólico Kaingang continua sendo reproduzido, modificado pelo contato, mas sem perder sua especificidade (TOMMASINO, 2000, p. 216).

No que toca à história ambiental, o estudo de Balduíno Rambo (1994) relata que, na primeira metade do século XX, em áreas da bacia hidrográfica do Taquari-Antas e Caí, animais como a onça, a anta, o bugio, o tamanduá e o papagaio poderiam ser encontrados. Entretanto, em relação à vegetação, informa que "[...] nos rios Taquari, Caí e dos Sinos, pouco resta das 
belas matas ribeirinhas de outrora, substituídas por milhares de plantações de arroz. Ao longo do Jacuí, o bárbaro sistema de converter em lenha para a capital tudo o quanto se prestasse para combustível alterou profundamente o aspecto primitivo da vegetação" (RAMBO, 1994, p. 180).

Referente às relações entre homem e natureza, aponta-se a própria nominação das terras indígenas, localizadas em territórios da bacia hidrográfica Taquari-Antas. Jamã Tü Tãnh, por exemplo, segundo os interlocutores Kaingang pesquisados, significa aldeia dos coqueiros ou os coqueiros, que também vivem aqui. Foxá, na língua Kaingang, é cedro, atribuição dada à terra indígena, conforme relatos Kaingang, em decorrência das várias árvores desta espécie no entorno da aldeia e também por ser o nome do bairro onde está localizada. Pó Mág significa pedra grande, em alusão a uma parede rochosa incrustada na moraria que circunda a Terra Indígena. Situação semelhante observa-se na Pó Nãnh Mág, localizada em áreas da bacia hidrográfica do Caí, cujo nome da Terra Indígena também faz alusão às montanhas e aos morros com araucárias, que, segundo as narrativas Kaingang, vivem próximos a eles.

Nas terras indígenas e no entorno onde cada uma das referidas aldeias está estabelecida, apesar da plantação de eucaliptos, observa-se a presença de expressiva vegetação composta de florestas nativas, capoeiras, gramíneas e pastagens. Considerando os etnoconhecimentos indígenas, foi identificada por interlocutores Kaingang a presença de espécies como guabirora (peguã), pitanga (jymy), açoita-cavalo (ketyjun), figueira (kevõfy), cedro (foxá), coqueiros (ténh tej), cerejeira (mér jór), araticum (kukrej), samambaia (angorô) e urtiga (korfe).

Conforme já mencionado, na cosmologia indígena, a natureza não está subordinada ao homem, sendo fundamental o respeito à biodiversidade de todas as espécies e, consequentemente, em muitas situações, a aprendizagem da linguagem dos animais, das plantas, dos ventos e da água, para as relações de reciprocidade com o ambiente. Segundo Rosa (2005), o ambiente Kaingang é composto de domínios xamânicos e entrecruzados: nível subterrâneo (espaço onde os antepassados Kaingag teriam permanecido com os ancestrais míticos Kamé e Kayrucre); nível mundo alto (mundo do céu e dos espíritos); e nível da terra (domínio da casa, do espaço limpo e da floresta), onde, respeitando-se a utilização dos recursos naturais, são definidas as zonas para a caça, a coleta, o cultivo e para as redes de relações intra e interaldeã. 
Em se tratando dos Kaingang, nosso tema de estudo, vale salientar que estes domínios estão presentes, pois continuam a acreditar na linguagem dos pássaros. A coruja, por exemplo, pode trazer avisos de coisas boas ou não; da taquara, a fibra é utilizada para cestaria; o gomo, para cortar o cordão umbilical dos recém-nascidos, e seus nós, para contagem do tempo; através do banho no rio, o espírito das águas pode levar os males embora; o etnoconhecimento de plantas como cancorosa, quina, pitanga, marcela, entre outras, cuja casca, tronco, flores e folhas são de uso medicinal, envolvendo o espírito da mata. Portanto, a história ambiental, a visão do ambiente e as relações do homem com a natureza, tanto no passado quanto no presente, aproxima-se da reflexão de Worster (1991, p. 201), ao afirmar que "quando ultrapassamos o mundo auto-refletido da humanidade e chegamos à esfera não-humana, a história ambiental encontra o seu principal tema de estudo".

\section{Comentários finais}

Considerando o território como fio analítico do estudo e estabelecendo novamente uma interlocução com Paul Elliot Little, com base no traba1ho, "Espaço, memória e migração: Por uma teoria de reterritorialização" (1994), que tratou dos indígenas Sioux das montanhas de Black Hills, é possível perceber que o espaço/memória Kaingang operacionalizado pelo mito fundante envolvendo a Serra do Crijijimbé, também engloba áreas do planalto, onde estão localizadas as bacias hidrográficas do Taquari-Antas e do Caí. Sendo assim, é neste espaço que projetam sua territorialidade (categoria envolvendo as relações sociais, políticas e simbólicas); nele também ocorriam as movimentações, respeitando os ciclos da natureza para a sustentabilidade (interpretados por nós como história ambiental); e também os conflitos com os colonizadores no século XIX, acarretando a fundação dos aldeamentos que impactaram diretamente no processo de (des)territorialidade indígena. Constata-se, por fim, que, no decorrer dos séculos XX e XXI, a política de aldeamentos, de toldos, de reservas e de postos indígenas não conseguiu confinar os Kaingang, os quais, acionando a memória e a continuidade de suas movimentações, levou ao processo de (re)territorialidade das comunidades Jamã Tÿ Tãnh, em Estrela; Foxá, em Lajeado; Pó Mág, em Tabaí; e Pó Nãnh Mág, em Farroupilha, onde as relações entre ser humano e natureza são orquestradas pela lógica indígena. 
LAROQUE, L. F. da S. • Movimentações e relações com a natureza dos Kaingang...

\section{Agradecimentos}

Ao CNPq, à Fapergs e à Univates pelo auxílio financeiro nos projetos de pesquisa, e à Univates pelo auxílio financeiro no projeto de extensão.

\section{Referências e fontes}

BAINES, Stephen Grant. As chamadas "aldeias urbanas" ou índios na cidade. Revista Brasil Indígena, Fundação Nacional do Índio, v. 7, p. 15-17, dez. 2001.

BECKER, Ítala Irene Basile. Dados sobre o abastecimento entre os índios Kaingang do Rio Grande do Sul conforme a bibliografia dos séculos XVI a XX. Estudos sobre o abastecimento indigena. Instituto Anchietano de Pesquisas. Publicações Avulsas, n. 2, p. 39-59, 1975.

BORBA, Telêmaco. Actualidade Indígena. Coritiba, Paraná, 1908. Curitiba: Impressora Paranaense, 1908.

BUBLITZ, Juliana. Forasteiros na floresta subtropical: notas para uma história ambiental da colonização alemã no Rio Grande do Sul. Ambiente e Sociedade, Campinas, v. XI, n. 2, p. 323-340, jul./dez. 2008.

BUSOLLI, Jonathan. A Terra Indígena Pó Mág, Tabaí/RS no contexto da reterritorialidade Kaingang em áreas da Bacia Hidrográfica Taquari-Antas. Monografia (Graduação em História), Centro Universitário Univates, Lajeado, 2015.

CORRÊA, Dora Shellard. Descrições de paisagens: construindo vazios humanos e territórios indígenas na capitania de São Paulo ao final do século XVIII. Varia Historia, Belo Horizonte, v. 24, n. 39, p. 135-152, jan./jun. 2008.

CORRESPONDÊNCIA de 19/12/1836. Correspondência do Corpo de Polícia de Taquari ao Presidente da Provincia Joze de Araújo Ribeiro. Arquivo Histórico do Rio Grande do Sul. s.n.

CORRESPONDÊNCIA de 15/02/1845. Correspondência de Francisco Mathias de Souze e Ávila, subdelegado de Polícia ao Sr. Juis de Direito e chefe de Polícia da Provincia Dr. Manoel José de Freitas Travassos. Arquivo Histórico do Rio Grande do Sul. Correspondência da Polícia. Maço 57.

CHRISTILLINO, Cristiano Luís. Estranhos em seu próprio chão: o processo de apropriações e expropriações de terras na Província de São Pedro do Rio Grande do Sul (O Vale do Taquari em período de 1840-1889). Dissertação (Mestrado em História da América Latina), Universidade do Vale do Rio dos Sinos (Unisinos), São Leopoldo, 2004.

DEAN, Warren. A ferro e fogo: a história e a devastação da Mata Atlântica brasileira. São Paulo: Companhia das Letras, 1996. 
GONÇALVES, Jaci Rocha. Relatório Final Antropologia na área de duplicação da BR386, Triunfo, Tabai, Taquari, Fazenda Vila Nova, Bom Retiro do Sul e Estrela-RS, Aldeia Kaingang TI Estrela. Tubarão: Universidade do Sul de Santa Catarina (Unisul), 2008. GREGORY, Josemir José. Fazenda da Estrella: um estudo de caso envolvendo posse territorial e negociações no sul do Brasil durante o século XIX. Lajeado-RS: Monografia (Graduação em História), Centro Universitário Univates, Lajeado, 2015.

IBGE - Instituto Brasileiro de Geografia e Estatística. Censo Demográfico 2010: Características gerais dos indígenas. Rio de Janeiro, 2012.

INVERNIZZI, Marina. Historicidade Kaingang na Terra Indigena Pó Nãnh Mág, em Farroupilha/RS. Monografia (Licenciatura em História). Centro Universitário Univates, Lajeado, 2015.

KÜHN, Fábio. Gente da fronteira: sociedade e família no sul da América portuguesa - século XVIII. In: GRIJÓ, Luís Alberto; KUHN, Fábio; GUAZZELI, César Augusto (Coords.). Capitulos de história do Rio Grande do Sul. Porto Alegre: Editora da UFRGS, 2004, p. 47-75.

LAPPE, Emeli. Espacialidades sociais e territoriais Kaingang: Terras Indígenas Foxá e Por Fi Gâ em contextos urbanos dos rios Taquari-Antas e Sinos. Dissertação (Mestrado em Ambiente e Desenvolvimento), Centro Universitário Univates, Lajeado, 2015.

LAPPE, Emeli; LAROQUE, Luís Fernando. Indígenas e Natureza: a reciprocidade entre os Kaingang e a natureza nas Terras Indígenas Por Fi Gâ, Jamã Tü Tãnh e Foxá. Desenvolvimento e Meio Ambiente, v. 34, p. 147-156, ago. 2015.

LAROQUE, Luís Fernando da Silva. Lideranças Kaingang no Brasil Meridional (1808-1889). Pesquisas Antropologia, n. 56, São Leopoldo: Instituto Anchietano de Pesquisas/Unisinos, 2000.

LAROQUE, Luís Fernando da Silva. Os Kaingangues; Momentos de historicidades indígenas. In: BOEIRA, Nelson; GOLIN, Tau (Orgs.). História Geral do Rio Grande do Sul - Povos Indígenas. Passo Fundo: Méritos, 2009, v. 5, p. 81-108.

LITTLE, Paul Elliot. Espaço, memória e migração. Por uma teoria de reterritorialização. Revista de Pós-Graduação em História da UNB, Brasília, v. 2, n. 4, p. 5-25, 1994.

MABILDE, Pierre F. A. B. Apontamentos sobre os Indígenas selvagens da Nação Coroados dos matos da Província do Rio Grande do Sul. São Paulo: IBRASA/Pró-memória/ INL, 1983.

MUSSI, Vanderléia Paes Leite. As estratégias de inserção dos índios Terena: da aldeia ao espaço urbano (1990-2005). Tese (Doutorado), Universidade Estadual Paulista, Assis, 2006. 
LAROQUE, L. F. da S. • Movimentações e relações com a natureza dos Kaingang...

NUNES, Eduardo Soares. Aldeias urbanas ou cidades indígenas? Reflexões sobre índios e cidades. Espaço Ameríndio, Porto Alegre, v. 4, n. 1, p. 9-30, jan./jun., 2010. NIMUENDAJÚ, Curt. Etnografia e indigenismo: sobre os Kaingang, os Ofaié-Xavante e os índios do Pará. Campinas: Editora da UNICAMP, 1993.

NONNENMACHER, Marisa Schneider. Aldeamentos Kaingang no Rio Grande do Sul: século XIX. Porto Alegre: EdiPUCRS, 2000.

OLIVEIRA, Roberto Cardoso de. Urbanismo e tribalismo. Rio de Janeiro: Jorge Zahar, 1968.

RAMBO, Balduíno. A fisionomia do Rio Grande do Sul: ensaio de monografia natural. 3. ed. São Leopoldo: Unisinos, [1942] 1994.

RAMOS, Alcida Rita. Sociedades Indigenas. São Paulo: Ática, 1988.

ROSA, Rogério Reus Gonçalves. "Os Kujá são diferentes": um estudo etnológico do complexo xamânico dos Kaingang da terra indígena de Votouro. Tese (Doutorado em Antropologia Social), Instituto de Filosofia e Ciências Humanas, Universidade Federal do Rio Grande do Sul, Porto Alegre, 2005.

ROSADO, Rosa Maris; FAGUNDES, Luiz Fernando Caldas (Orgs.). Presença indígena na cidade: reflexões, ações e políticas. Realização Núcleo de Políticas Públicas para Povos Indígenas. Porto Alegre: Gráfica Hartmann, 2013.

SEEGER, Anthony; CASTRO, Eduardo B. Viveiros de. Terras e territórios indígenas do Brasil. Encontros com a Civilização Brasileira. Rio de Janeiro, n. 12, p. 101-113, 1979.

SILVA, Juciane Beatriz Sehn da. "Eles vira que o Índio tem poder, nér": o protagonismo Kaingang da Terra Indígena Jamã Tÿ Tãnh/Estrela diante do avanço desenvolvimentista de uma Frente Pioneira. Dissertação (Mestrado em Ambiente e Desenvolvimento), Centro Universitário Univates, Lajeado, 2016.

SILVA, Riograndino da Costa e. Notas à margem da História do Rio Grande do Sul. Porto Alegre: Globo, 1968.

SOUZA, Ana Hilda Carvalho; HAETINGER, Claus; LAROQUE, Luís Fernando da Silva. A busca pelo reconhecimento da identidade étnica Macuxi e Wapichana no contexto urbano de Boa Vista, Roraima, Brasil. Multitemas, Campo Grande, v. 21, n. 50, p. 51-82, jul./dez.. 2016.

TOMMASINO, Kimiye. A história dos Kaingang da bacia do Tibagi: uma Sociedade Jê Meridional em movimento. Tese (Doutorado em Antropologia), Faculdade de Filosofia, Letras e Ciências Humanas de São Paulo, São Paulo, 1995.

TOMMASINO, Kimiye. Homem e natureza na ecologia dos Kaingang da Bacia do Tibagi. In: TOMMASINO, Kimiye; MOTA, Lúcio Tadeu; NOELLI, Francisco Silva (Orgs.). Novas contribuições aos estudos interdisciplinares dos Kaingang. Londrina: Eduel, 2004, p. 355-413. 
TOMMASINO, Kimiye. Território e territorialidade Kaingang. Resistência cultural e historicidade de um grupo Jê. In: MOTA, Lúcio Tadeu; NOELLI, Francisco Silva; TOMMASINO, Kimiye (Orgs.). Urí e Wãsi-Estudos Interdiciplinares dos Kaingang. Londrina: Ed. UEL, 2000, p. 191-226.

VEDOY, Moíses Ilair Blum. Contatos Interétnicos: Sesmeiros, fazendeiros, imigrantes alemães e indígenas Kaingang em territórios das bacias hidrográficas do Taquari-Antas e Caí. Lajeado: Monografia (Graduação em História), Centro Universitário Univates, Lajeado, 2015.

WOLF, Sidnei. Arqueologia Jê no alto Forqueta e Guaporé/RS: um novo cenário para um antigo contexto. Lajeado: Tese (Doutorado em Ambiente e Desenvolvimento), Centro Universitário Univates, Lajeado, 2016.

WORSTER, Donald. Para fazer história ambiental. Estudos Históricos. Rio de Janeiro, v. 4, n. 8, p. 198-215, 1991. 